\title{
Percepção dos profissionais da saúde sobre o parto de cócoras
}

\author{
Perception of healthcare professionals about childbirth in squatting position
}

Percepción de los profesionales de la salud sobre el alumbramiento en posición de cuclillas

Ana Paula Costella ${ }^{1}$, Gabriela da Silva Garcia Faller ${ }^{2 *}$, Gabriela Laste ${ }^{1}$.

\begin{abstract}
RESUMO
Objetivo: Analisar a percepção dos profissionais da saúde sobre o parto de cócoras. Métodos: trata-se de uma pesquisa qualitativa com abordagem descritiva, exploratória, realizada em uma Unidade Hospitalar Filantrópica, no interior do Rio Grande do Sul, Brasil. Os sujeitos participantes foram enfermeiros, técnicos de enfermagem e médicos através de entrevistas com questões norteadoras, que foram gravadas, transcritas e analisadas. Resultados: Foram 10 profissionais entrevistados que atuavam no centro obstétrico. Evidenciouse 04 categorias, sendo elas: 1) Conhecimento dos profissionais da saúde sobre o parto de cócoras; 2) Dificuldade/facilidade na adesão do parto de cócoras; 3) Envolvimento dos profissionais de saúde frente oferta e incentivo da posição; 4) Informações e Ações importantes a serem repassadas a parturiente. Conclusão: Foi demonstrado as dificuldades dos profissionais frente ao parto de cócoras, bem como seu engajamento no processo de humanização do parto. Sendo assim, o estudo contribui para a reflexão dos profissionais da saúde perante as práticas em saúde, assim como promove o reconhecimento e a valorização da equipe da enfermagem quando falamos em adoção de conhecimentos e ações humanísticas de parturição.
\end{abstract}

Palavras-chave: Parto normal, Humanizado, Trabalho de parto, Profissionais da saúde, Assistência ao parto.

\begin{abstract}
Objective: Analyze the perception of health professionals about squatting birth. Methods: Qualitative research with a descriptive, exploratory approach, carried out in a Philanthropic Hospital Unit, in the interior of Rio Grande do Sul, Brazil. Participants were nurses, nursing technicians and doctors through statements with guiding questions, which were recorded, transcribed and analyzed. Results: There were 10 professionals interviewed who worked in the obstetric center. 4 categories were evidenced, namely: 1) Knowledge of health professionals about squatting birth; 2) Difficulty / ease of adherence to squatting delivery; 3) Involvement of health professionals in terms of offering and encouraging the position; 4) Important information and actions to be passed on to the parturient. Conclusion: The difficulties faced by professionals in squatting delivery were demonstrated, as well as their engagement in the humanization process of childbirth. Thus, the study contributes to the reflection of health professionals on health practices, as well as promoting the recognition and appreciation of the nursing team when we talk about the adoption of humanistic knowledge and actions in parturition.
\end{abstract}

Keywords: Normal delivery, Humanized, Labor, Health professionals, Delivery assistance.

\section{RESUMEN}

Objetivo: Analizar la percepción de los profesionales de la salud sobre el parto en cuclillas. Métodos: Se trata de una investigación cualitativa con abordaje descriptivo, exploratorio, realizada en una Unidad Hospitalaria Filantrópica, en el interior de Rio Grande do Sul, Brasil. Los sujetos participantes fueron enfermeros, técnicos de enfermería y médicos a través de entrevistas con preguntas orientadoras, las cuales fueron grabadas, transcritas y analizadas. Resultados: Se entrevistaron 10 profesionales que laboraban en el centro obstétrico. Se evidenciaron cuatro 4 categorías, a saber: 1) Conocimiento de los profesionales de la salud sobre el parto en cuclillas; 2) Dificultad / facilidad de adherencia al parto en cuclillas; 3) Implicación de los profesionales de la salud en la oferta y promoción del puesto; 4) Información importante y acciones a transmitir a la parturienta. Conclusión: Se demostró las dificultades de los profesionales que enfrentan el parto en cuclillas, así como su implicación en el proceso de humanización del parto. Así, el estudio contribuye a la reflexión de los profesionales de la salud sobre las prácticas de salud, así como a promover el reconocimiento y la valoración del equipo de enfermería cuando hablamos de la adopción de conocimientos y acciones humanísticas en el parto.

Palabras clave: Parto normal, Humanizado, Trabajo de parto, Profesionales de la salud, Asistencia al parto.

1 Universidade do Vale do Taquari (Univates), Lajeado - RS. *E-mail: gabrielalaste@univates.br

2 Hospital Bruno Born, Lajeado - RS.

SUBMETIDO EM: 10/2021 


\section{INTRODUÇÃO}

A gestação e o parto são acontecimentos na vida da mulher que envolvem cuidados e adaptações principalmente fisiológicas, emocionais, interpessoais, culturais e sociais. Entende-se que é um acontecimento singular, constituído de uma experiência humana significativa da qual as mulheres fazem parte. A atenção humanizada é imprescindível durante o parto, como forma de reconhecimento e respeito aos direitos humanos (BRASIL, 2011; PIASZAK GM, et al., 2013).

O parto humanizado deve respeitar o processo fisiológico de cada mulher, evitando realizar procedimentos desnecessários, conhecendo os aspectos sociais e culturais individualmente (GIANTAGLIA FN, et al., 2017). Os profissionais da saúde devem utilizar todos os métodos não farmacológicos que auxiliem no alívio da dor da gestante antes do parto, explicando as condutas e passos tomados pela equipe. Ainda, é importante que os profissionais salientem as dúvidas referentes ao parto e esclareçam para a gestante as possíveis formas de alívio, fazendo com que se sinta confortável e segura (BRASIL, 2017).

O uso de intervenções não farmacológicas, como a liberdade de posição, são tecnologias não invasivas de baixo custo e acessíveis para oferta em todos os serviços de saúde (LEAL MC, et al., 2014). A equipe de enfermagem deve encorajar a mulher a ficar em posição supina, decúbito dorsal horizontal ou posição semisupina no período do trabalho de parto e ser incentivada a adotar qualquer posição que the proporcionará conforto, incluindo as posições de cócoras, lateral ou quatro apoios (BRASIL, 2017). Nesse sentido, a posição de Fowler ou de cócoras, abordada neste estudo, facilita a mulher realizar mais força durante o nascimento do bebê, além de auxiliar no nascimento (BRASIL, 2013).

O uso da banqueta deve ocorrer quando a mulher atingir dilatação de 8 centímetros e o feto precisar fazer o processo de descida, assim auxiliará na descida e rotação fetal deixando livre a região vulvo-perineal (FREITAS JC, et al., 2021). Evidências científicas internacionais, reportam que a posição litotômica no momento do parto ocasiona o aumento de partos instrumentados, dor perineal e frequência cardíaca fetal não tranquilizadora (ROCHA BD, et al., 2020). Já a posição verticalizada, em especial a de cócoras, possui diversos benefícios e pode envolver a participação do seu acompanhante, dando apoio físico e emocional à gestante (BRASIL, 2013).

Entretanto, enfermeiras obstetras e obstetrizes são chaves fundamentais para a implementação das evidências científicas na rotina dos serviços de saúde (ROCHA BD, et al., 2020). Nesse sentido, o objetivo deste estudo foi analisar a percepção dos profissionais da saúde sobre o parto de cócoras.

\section{MÉTODOS}

Esta é uma pesquisa descritiva, exploratória, e com abordagem qualitativa. O estudo foi realizado em uma Unidade Hospitalar Filantrópica, no interior do Rio Grande do Sul, no Sul do Brasil, com média populacional de setenta mil habitantes. A Unidade é de direito privado com mais de oitenta anos de atuação, sendo referência em diversas especialidades de saúde de média ou alta complexidade, com aprimoramento constante em recursos físicos, técnicos e humanos. O serviço tem missão, visão e valores com seus clientes, vislumbrando o bom senso, resolutividade, humanismo e sustentabilidade.

Foram entrevistados profissionais da saúde que estavam disponíveis em cada turno de trabalho das categorias incluídas no estudo, que atendiam os critérios de inclusão: todos os turnos de trabalhos e de todas as faixas etárias que atuavam no centro obstétrico. Foram excluídos profissionais da área da saúde que se encontram de férias, folgas, licença saúde, maternidade e os que não atinjam 06 meses de atuação na unidade.

Utilizou-se diversas etapas com finalidade de realizar a coleta de dados necessária para obter o resultado da pesquisa. Em primeiro momento, contatou-se a unidade hospitalar para devida ciência do objetivo do estudo, após solicitou-se uma sala para encontros com a equipe do centro obstétrico. A coleta de dados ocorreu durante o primeiro semestre do ano de 2021, por meio de entrevista individual, com questões norteadoras, com média de trinta a quarenta minutos com cada profissional, variando de acordo com o tempo de trabalho ou experiências, sendo todas gravadas. 
Após a coleta de dados, os dados foram transcritos e analisados conforme Análise de Conteúdo, sendo construído categorias temáticas (BARDIN L, 2016). Os participantes da pesquisa foram identificados por área de atuação, med 1, med 2, med 3, enf 1, enf 2 , enf 3 , enf 4 , tec 1 , tec 2 e tec 3 . Em nenhum momento da pesquisa objetivou-se a identificação dos profissionais, mantendo suas identidades preservadas.

Este estudo seguiu a Resolução Ministerial do Conselho Nacional de Saúde № 466/2012, que regulamenta as pesquisas com seres humanos (BRASIL, 2012). O projeto foi aprovado pelo Comitê de Ética em Pesquisa, com parecer consubstanciado no 4.481.570. Garantiu-se cuidados éticos a todos os profissionais que assinaram duas vias do Termo de Consentimento Livre e Esclarecido.

\section{RESULTADOS}

Foram entrevistados 10 profissionais que atuavam no centro obstétrico. Dentre esses foram: 03 médicos, 04 enfermeiros e 03 técnicos de enfermagem. Houve uma recusa de participação pelo profissional de subentender que não auxiliaria em nenhum momento da pesquisa.

A análise de dados evidenciou 04 categorias, sendo elas: 1) Conhecimento dos profissionais da saúde sobre o parto de cócoras; 2) Dificuldade/facilidade na adesão do parto de cócoras; 3) Envolvimento dos profissionais de saúde frente oferta e incentivo da posição; 4) Informações e Ações importantes a serem repassadas a parturiente.

Quanto à característica atuação dos profissionais entrevistados, a categoria médica possuia faixa etária de 20 a 40 anos e de atuação como profissional de 8 a 15 anos. Os enfermeiros participantes da pesquisa tinham entre 25 a 35 anos e atuação profissional de 02 a 08 anos e a classe dos técnicos de enfermagem tinham de 28 a 60 anos e atuavam há 1 a 10 anos.

\section{Conhecimento dos profissionais da saúde sobre o parto de cócoras}

Buscou-se compreender o conhecimento e percepção dos participantes sobre o parto de cócoras. Todos relataram conhecer o parto durante sua trajetória acadêmica e profissional, porém nem todos conseguiram detalhar sobre a posição.

Sendo assim, as classes médica e de enfermagem (nível técnico) relataram ter conhecimento, porém sem detalhar a posição:

"Conhecimento, não, eu tenho conhecimento, faço parto na posição de cócoras, conheço parto sim, faço parto sim” (Méd. 1).

"O parto de cócoras, eu sei que ele existe, que é feito também aqui [...]" (Téc. 3).

Apesar disso, a maioria especificou sobre suas percepções e benefícios da posição:

"Conhecimento então que é uma posição fisiológica ela é uma posição natural da mulher ao parir muitas assumem essa posição naturalmente" (Enf. 4).

"[...] o que eu conheço do parto na posição de cócoras é que é a posição que mais facilita o parto normal" (Enf. 2).

"[...] então assim o parto de cócoras ele vai ser a paciente então agachada, ela tem que ter um maior controle sobre a força dela, da respiração, da posição, a banqueta auxilia na posição, mais ou menos isso" (Méd. 2).

"O meu conhecimento é que auxilia né, na descida do bebê [...]" (Téc. 1).

\section{Dificuldade/facilidade na adesão do parto de cócoras}

Percebeu-se que apesar de todos os profissionais da saúde relatarem conhecer a posição de cócoras, nem todos aderem-a devido aos entraves que eles mesmos relataram. Esses fatores estavam relacionados a dificuldade de aderência da paciente a posição devido desconforto, cansaço, dor, aspecto cultural, medo: 
"[...] o que dificulta às vezes é a paciente não querer, porque às vezes a paciente quer, tu oriente que ela pode ficar como ela quiser, que ela pode ficar em pé, que ela pode ficar sentada e às vezes a paciente quer deitar, deitar, deitar, porque ela já tem aquela coisa cultura [...]" (Méd. 3).

"[...] elas cansam, no banquinho elas acabam se jogando [...]" (Méd. 2).

"[...] elas têm medo, muitas vezes desta posição, que vai sair o meu bebê, e eu não, vai cair ou alguma coisa assim [...]" (Enf. 1).

Outro fator, relatado pela enfermagem foi falta de autonomia do enfermeiro obstetra. Ainda destacaram que a adesão ao parto de cócoras se dá principalmente quando os profissionais médicos não se fazem presentes ou estão de acordo com a atuação do enfermeiro:

"[...] gente faz os partos, como enfermeira é tranquilo de fazer o parto, a gente não se importa de ficar no chão, mas os médicos a gente vê que eles não gostam sentar no chão, de ficar naquela posição de quatro, e tal, então eles não tem muita paciência, mas eles não nos contraindicam que a gente deixe ela até o período expulsivo" (Enf. 3).

"[...] quando o médico obstetra liberar, né, diz assim, ah, faz, o que vocês acharem melhor, a gente toma conta e a gente consegue, mas depende muito disso né, porque aqui o enfermeiro não tem muita autonomia, em relação aos partos" (Enf. 2).

"[...] o enfermeiro obstetra ele não tem muita autonomia aqui na realidade, nessa realidade aqui, nessa instituição, mas quando o médico obstetra liberar" (Enf. 2).

Adicionalmente, um profissional médico referiu que no período expulsivo na banqueta podem ocorrer intercorrências devido a dificuldade de visualização e proteção do períneo:

"[...] no parto de cócoras eu não tenho, eu não consigo ter acesso ao períneo posterior da paciente, ou seja, eu não consigo proteger o períneo da paciente [...]" (Méd. 2).

Outras dificuldades relatadas por médicos foram em relação a sangramento e lacerações:

"Sangra mais" (Méd. 1).

"[...] então as pacientes que têm parto de cocoras ainda mais que elas conseguem fazer um pucho mais importante, geralmente tem lacerações bem maiores, $e$ lacerações que tem compremetimento posterior, inclusive lesões de 3grau, 4 grau, com lesões de isfincter anal, e tudo mais [...]" (Méd. 2).

\section{Envolvimento dos profissionais de saúde frente oferta e incentivo}

Percebeu-se que a maioria dos profissionais relataram incentivar e ofertavam todas as posições à parturiente. Sendo assim, incentivavam a autonomia e protagonismo da paciente no momento de parir:

"Geralmente eu ofereço todas as posições né, até achar uma que a paciente se sinta mais confortável, né, mas é bem indicado [...]" (Téc. 1).

"[...] quando eu pego uma gestante que está em início de trabalho de parto, eu indico, eu falo com elas, todas as posições possíveis, que a gente tem no período de expulsão, porque eu ainda vejo que tem muita falha no pré- natal" (Enf. 3).

"Envolvimento é deixar a paciente à vontade, entender, falar o que eu tenho de posição para fazer, e a paciente escolhe como quer ficar" (Méd. 1)

Apesar de incentivarem, houve relatos por parte da classe médica, a qual não finalizam o parto na posição de cócoras. Os motivos seriam no caso de primigesta, dificuldade de acesso ao períneo ou pelo bebê ser muito grande, o que dificultaria o nascimento: 
"Não indicaria. Não indico, porque além de a paciente ter que se dedicar muito antes e isso poucas fazem, no parto de cócoras eu não tenho, eu não consigo ter acesso ao períneo posterior da paciente, ou seja, eu não consigo proteger o períneo da paciente" (Méd. 2).

"[...] ter parto exatamente na posição primigesta é mais difícil, tá. principalmente quando eu tenho uma suspeita que seja um neném maior, que tenha que fazer alguma manobra eu não consigo fazer essa manobra ali não. Ali nestes casos reservados, ai sim eu não indico" (Méd. 1).

Em contrapartida, um profissional além de incentivar finalizava o parto na posição de cócoras.

"Eu indicaria, e indico sempre, acho uma posição, que já é fisiológica, então ela tem, tipo assim, inclusive, é uma posição que a gente usa bastante para aqueles bebês que estão insinuados muito tempo, assim, no canal do parto, eu acho que funciona muito, tem inclusive registros de paciente de cócoras, eu acho que funciona muito [...]" (Méd. 3).

\section{Informações e ações importantes a serem repassadas a parturiente}

Os relatos trouxeram a importância do ser humanizado, oferta de informações claras às parturientes para que elas se sintam acolhidas e entendam o que está sendo ofertado a elas:

"Tem que falar tudo que facilita e é bom, pra ela né. Pra ela e pro bebe, né. Daí vou falar, falar tudo, do jeito que ela entenda [...]" (Enf. 2).

"[...] eu costumo deixar a paciente muito a vontade porque ela quer fazer, mas eu procuro, hã, orientar a paciente, a tentar outras coisas que ela se sinta mais confortável [...]" (Méd. 3).

"Eu acho que todas as posições deveriam ser sempre bem definidas bem explicadas por toda a equipe médico de enfermeiro por que isso é importante. Isso faz parte do ser humanizado e muitas vezes não é sobre exercícios posições é sobre espaço com a paciente carinho conversa e explicações [...]" (Enf. 1).

A classe dos profissionais médicos trouxe a importância da fisioterapia durante o pré-natal como forma de preparação e informação para o momento do parto:

"Ela teria que fazer então durante todo o pré-natal fisioterapia pélvica, para ter controle do esfíncter dela e controle do pucho [...]" (Méd. 2).

"[...] eu encaminho as minhas pacientes principalmente aquelas que querem, que já verbalizam desde o começo do pré-natal que querem que querem parto que elas que elas consultem com alguém da Fisio porque eu acho que super funciona" (Méd. 3).

\section{DISCUSSÃO}

A partir de todos os relatos obtidos, percebeu-se que os profissionais conheciam e incentivaram a posição de cócoras, da banqueta e agachada e respeitavam a liberdade de posição. Os profissionais da enfermagem relataram incentivar a parturiente a ficar na posição e finalizavam o parto caso fosse da escolha da parturiente. Entretanto, a falta de autonomia desses profissionais foi um entrave encontrado durante o processo de nascimento. Contudo, apesar da classe médica incentivar a permanência de cócoras, não finalizava o parto nesta posição.

A literatura atual reporta que as posições verticalizadas no segundo período de trabalho de parto reduzem o período expulsivo, bem como diminuem a necessidade de episiotomia. Entretanto, pode estar relacionada com o aumento de lacerações perineais bem como perda sanguínea superior a $500 \mathrm{ml}$, isto corrobora com relatos de alguns profissionais participantes do nosso estudo (GUPTA JK, et al., 2017). Em contrapartida, em 
revisão sistemática e metanálise em que os autores compararam a posição de cócoras com posições litotómicas e obtiveram que de 500 mulheres da amostra, 44\% apresentaram períneo íntegro comparadas com as $17 \%$ que adotaram posições litotomicas. Além do mais, o estudo concluiu que existem diversos benefícios quando adotado posições verticalizadas durante o processo de parir, principalmente na rotação de bebês (ROCHA BD, et al., 2020).

Em um estudo realizado sobre percepções das gestantes sobre as posições de parto, notou-se no quesito percepções sobre as posições verticalizadas, que as mulheres avaliaram como uma experiência positiva. E, analisando os relatos foi possível compreender impressões e sensações, como a rapidez da descida do feto, diminuição de intervenções e interferências profissionais, bem como maior conforto durante os puxos. Relataram ainda, ter medo de que seu filho caísse no chão. Apesar dos possíveis riscos e benefícios das posições, deve-se permitir que sejam oferecidas todas as posições às parturientes e que ela tenha autonomia de ser protagonista no processo de Nascimento (SOUSA JL, et al., 2018).

A maioria dos profissionais relataram incentivar e ofertar todas as posições para à parturiente, bem como a liberdade de escolha durante o processo de nascimento. A liberdade da escolha da posição é um dos benefícios do parto normal, pois a parturiente pode caminhar, de modo que ela se sinta mais confortável, diminuindo as intervenções desnecessárias (SILVA DF, et al., 2018).

Além do incentivo ao pré-natal, os profissionais da classe médica indicaram a procura de um fisioterapeuta para a realização do fortalecimento pélvico, este poderia auxiliar na preparação da gestante no processo de nascimento e compreensão do seu corpo. Em um estudo, objetivou-se conhecer a satisfação das puérperas quando questionadas sobre o parto normal. Obteve-se como resultado, que o profissional fisioterapeuta não é uma prática comum nos serviços de saúde. Apesar disso, o mesmo contribuiria para a preparação do parto, o qual pode ser indicado desde o início da gestação. Acreditando que a intervenção deste profissional favoreça a adesão ao parto normal, a fisioterapia pélvica é essencial no preparo do assoalho pélvico, durante o processo de gestação, facilitando a fase expulsiva e reduzindo a possibilidade de lacerações graves na musculatura perineal (CHIVA VEC, et al., 2020).

Apesar dos benefícios e das indicações da fisioterapia pélvica, sabe-se que a maioria das unidades básicas de saúde não dispõem de um fisioterapeuta, pois não integram a equipe mínima. Desta forma as gestantes teriam que buscar outros meios alternativos, o que por sua vez, podem ser um empecilho para as pessoas de baixa renda. Apesar de ter relacionado com a incontinência urinária, demonstrou-se falta de conhecimento sobre a atuação/importância do fisioterapeuta pélvico e a falta de oferta deste serviço na rede pública de saúde (NETO AGC, et al., 2018). Portanto, a implementação de um profissional fisioterapeuta na rede de saúde pública, aumentaria $o$ atendimento e facilitaria as adaptações às mudanças corporais ocorridas durante a gestação e parto (CHIVA VEC, et al., 2020).

Durante o processo de nascimento, nossos resultados demonstraram que a classe da enfermagem buscava acolher de forma humanizada e tranquilizadora as parturientes, auxiliando-as nas escolhas do processo de nascimento. É importante que os enfermeiros tenham boas práticas e soluções efetivas no momento do nascer, bem como promovam a afetividade e segurança, melhorando o grau de informação das mulheres, baseado em políticas e práticas de saúde (CARVALHO SS, 2019).

Essas práticas devem ainda, promover o acolhimento, escuta ativa e buscar o uso da tecnologia apropriada a cada caso (BRASIL, 2011). Humanizar, no contexto deste estudo, priorizou o cuidado obstétrico e o respeito à fisiologia do parto, tendo a mulher como protagonista no processo de parturição (MEDEIROS RMK, et al., 2016).

Apesar do engajamento dos profissionais da enfermagem, a realização do nascimento ainda é dada pela classe médica. São notáveis questões de empecilho, quando fala-se da autonomia do enfermeiro, devido à presença do modelo biomédico, o qual ainda é limitador para o efetivo exercício da autonomia. Apesar dos enfermeiros relatarem não ter autonomia para realização do parto, quando o profissional médico faz presente, nota-se que as práticas distintas entre os profissionais são necessárias para a prestação de serviços sejam constituídas de forma coletiva e entre compartilhamento profissional (MELO CCM, et al., 2016). 
Cabe ressaltar que a resolução do Conselho Federal de Enfermagem (COFEN), no Art.3으, IV, reporta que o profissional enfermeiro que estiver habilitado como enfermeiro obstétrico, pode avaliar a evolução do parto, condições maternas e fetais, além do mais podem adotar medidas pelas quais acharem apropriadas na assistência e tomada de decisão, respeitado a autonomia e protagonismo da mulher (COFEN, 2016).

As limitações deste estudo estão relacionadas a sua realização em um único local, bem como a dificuldade na coleta de dados, devido ao período pandêmico e sobrecarga de trabalho dos profissionais. Desse modo, sugere-se que novos estudos sejam feitos com mais participantes para que se possa contemplar ainda mais questões que não estão elucidadas nessa pesquisa. Entretanto, o estudo contribui para a reflexão dos profissionais da saúde, perante as práticas em saúde, as quais podem ser ampliadas ou melhoradas, quando falamos de humanização. Ademais, o estudo promove o reconhecimento e a valorização da equipe da enfermagem quando falamos em adoção de conhecimentos e ações humanísticas de parturição.

\section{CONCLUSÃO}

O estudo elucidou questões sobre a percepção dos profissionais relativos ao parto de cócoras. Percebeuse as dificuldades dos profissionais frente ao parto, bem como seu engajamento no processo do nascimento. É relevante que se tenham medidas para garantir o aprimoramento da assistência ao paciente, bem como a forma como os profissionais se inserem no momento da partolândia. Muito ainda deve ser melhorado por alguns profissionais de todas as classes do estudo, desmistificando o olhar voltado para saúde/doença e criando um olhar humanizado e integral aos usuários dos sistemas de saúde.

\section{REFERÊNCIAS}

1. BARDIN L. Análise de Conteúdo. 3a reimp. São Paulo: Edições 70, 2016; 277p.

2. CARVALHO SS, et al. Revisão integrativa: promoção das boas práticas na atenção ao parto normal. Rev. Aten. Saúde, 2020; 18(63): 110-119.

3. CHIBA VEC, et al. Avaliação do preparo dos músculos do assoalho pélvico na assistência pré-natal. Revista Brasileira de Saúde Funcional, 2020; 11(1): 51-60.

4. CONSELHO FEDERAL DE ENFERMAGEM (COFEN). Resolução № 516/2016. 2016. Disponível em: http://www.cofen.gov.br/resolucao-cofen-no-05162016_41989.html. Acessado em: 22 de setembro de 2021.

5. BRASIL. Resolução №466/2012. 2012. Disponível em: Acessado em: 22 de setembro de 2021.

6. BRASIL. Diretrizes Nacionais de Assistência ao Parto Normal. 2017. Disponível em: https://bvsms.saude.gov.br/bvs/publicacoes/diretrizes_nacionais_assistencia_parto_normal.pdf. Acessado em: 22 de setembro de 2021.

7. BRASIL. Família brasileira fortalecida: pré-natal, parto e pós parto. 2013. Disponível em: https://www.unicef.org/brazil/sites/unicef.org.brazil/files/2019- 03/br_kit_fbf_album1_2013.pdf. Acessado em: 22 de setembro de 2021.

8. BRASIL. Parto, Aborto e Puerpério Assistência Humanizada à Mulher. 2001. Disponível em: http://bvsms.saude.gov.br/bvs/publicacoes/cd04_13.pdf. Acessado em: 22 de setembro de 2021.

9. BRASIL. Política Nacional de Atenção Integral à Saúde da Mulher: Princípios e Diretrizes. 2011. Disponível em: https://bvsms.saude.gov.br/bvs/publicacoes/politica_nacional_mulher_principios_diretrizes.pdf. Acessado em: 22 de setembro de 2021.

10. FREITAS JC, et al. Eficácia dos métodos não farmacológicos para alívio da dor no trabalho de parto natural: uma revisão integrativa. Revista Eletrônica Acervo Enfermagem, 2021; 12: 1-9.

11. GIANTAGLIA FN, et al. O cuidado de enfermeiras de um programa de residência obstétrica sob o olhar da humanização. Rev. de Enfermagem, 2017; 11(5): 1882-1890.

12. GUPTA JK, et al. Position in the second stage of labour for women without epidural anaesthesia. Cochrane Database of Systematic Reviews, 2017; 5(5): 01-96.

13. LEAL MC, et al. Intervenções obstétricas durante o trabalho de parto em mulheres brasileiras de risco habitual. Caderno de Saúde Pública, 2014; (1)1: 17-32.

14. MEDEIROS RMK, et al. Cuidados humanizados: a inserção de enfermeiras obstétricas em um hospital de ensino. Revista Brasileira de Enfermagem, 2016; 6(69): 1029-1036.

15. MELO CMM, et al. Autonomia profissional da enfermeira: algumas reflexões. Escola Anna Nery 2016; 20(4): e20160085.

16. NETO AGC, et al. Avaliação do conhecimento sobre o tratamento fisioterápico da incontinência urinária de esforço entre gestantes e puérperas atendidas na rede pública de saúde do município de Patrocínio - MG. Revista Interdisciplinar de Promoção de Saúde (RIPS), 2018; 1(1): 41-45.

17. PIASZAK GM, et al. Percepção dos profissionais de enfermagem acerca do cuidar em centro obstétrico. Revista Rene, 2013; 3: 568-578.

18. ROCHA BD, et al. Posições verticalizadas no parto e a prevenção de lacerações perineais: revisão sistemática e metanálise. Revista da Escola de Enfermagem da USP, 2020; 54: e03610.

19. SILVA DF, et al Conhecimento das gestantes sobre as posições do parto. Revista da Enfermagem da FACIPLAC, 2018; 1(1)

20. SOUSA JL, et al. Percepção de puérperas sobre a posição vertical no parto. Revista Baiana de Enfermagem, 2018; 32: e27499. 